\title{
A Study on the Application of Code Theory in the Decorative Design of Taiwan Bamboo Tube Furniture
}

\author{
Shih-Hsing $\mathrm{Wu}^{1, *}$, Kuo-Kuang Fan ${ }^{2}$ and Chuan-Jen Sun ${ }^{3}$ \\ 1 Doctoral Program, Graduate School of Design, National Yunlin University of Science and Technology, \\ Douliou, Yunlin 64002, Taiwan \\ 2 Graduate School of Design, National Yunlin University of Science and Technology, Douliou, \\ Yunlin 64002, Taiwan; fankk@yuntech.edu.tw \\ 3 Department of Visual Communication Design, TransWorld University, Douliou, Yunlin 64002, Taiwan; \\ manoa.tw@gmail.com \\ * Correspondence: wuhsing.wuhsing@msa.hinet.net; Tel.: +886-953-670-706
}

Citation: Wu, S.-H.; Fan, K.-K.; Sun, C.-J. A Study on the Application of Code Theory in the Decorative Design of Taiwan Bamboo Tube Furniture. Sustainability 2021, 13, 3722 https://doi.org/10.3390/su13073722

Academic Editor: Yuri Borgianni

Received: 16 February 2021

Accepted: 19 March 2021

Published: 26 March 2021

Publisher's Note: MDPI stays neutral with regard to jurisdictional claims in published maps and institutional affiliations.

Copyright: (c) 2021 by the authors. Licensee MDPI, Basel, Switzerland. This article is an open access article distributed under the terms and conditions of the Creative Commons Attribution (CC BY) license (https:/ / creativecommons.org/licenses/by/ $4.0 /)$.

\begin{abstract}
Taiwan has an abundance of the environmentally-friendly resource bamboo, as well as longstanding Chinese bamboo customs and culture. As a result, modest bamboo furniture accompanies the simple life of Taiwan's residents. However, as people prosper, consumers are beginning to choose bamboo furniture for its decorative design and style more than for its practicality. Therefore, the symbolic application of decorative art is worthy of research and discussion. The purpose of this research is to use codes to explore the decorative design of bamboo tube furniture and enlighten Taiwan's new direction of bamboo furniture design in the future. Through literature content analysis, field expert interviews, and practical experience participation methods, in addition to using function codes, emotion codes, transmission codes, and identification codes to interpret the Han Dynasty's Liushu and Chinese bamboo cultural content, we verify the relevance of the code and bamboo furniture decoration and provide interactive new thinking and creative products.
\end{abstract}

Keywords: bamboo tube furniture; bamboo culture; code theory; environmentally friendly materials; decorative design style

\section{Introduction}

The United Nations' Sustainable Development Goal 15 is called "Life on Land" [1]. Bamboo has become a green material because of its rapid growth, non-toxicity, and recyclability. Due to its high carbon storage and low afforestation cost, it is a suitable natural-based solution to alleviate climate change [2]. Therefore, bamboo is a suitable material for the ecosystem.

As countries in the world attach increasing importance to environmental awareness and the use of environmentally friendly materials in the 21st century, adopting bamboo material has gradually become mainstream in today's furniture design [3,4]. This has been studied by some well-known architects and scholars, for example: Ghavami K. in his "Purpose of Research", applies physical, mechanical, and structural characteristics to help bamboo professionals to conveniently use bamboo as a structural element to select the required size, such as diameter, thickness and internode distance, various stress and mechanical properties [5]; Sonpal B. (2015) of South Korea, home of the 10th World Bamboo Festival, in the paper "Relooking at bamboo: A journey into exploration of bamboo components for structural possibilities", tried to use bamboo for experimental research, aiming to study the obtained modules/systems structural behavior, performance under different load condition, and the structural potential of the material is to be harnessed fully [6]; Vos V.'s 2010 thesis "International Timber Trade, Bamboo used for external joinery" is a study of material properties and market prospects, which describes bamboo used in the market as external joinery, and changes and uses of bamboo composite materials, such as the use of laminated bamboo [7]. 
Since the 1990s, industrial designers in various countries have been committed to environmental protection, and green materials have gradually become the first choice of designers [8,9]. Many countries with bamboo resources have begun to use them to develop green products [10]. Due to the rapid growth of bamboo products, they not only represent new business opportunities but also reduce the negative environmental impact $[3,4,10,11]$. The above-mentioned scholars focus on the structural improvement of environmentally friendly bamboo materials and the development in response to the market. This behavior is inseparable from the scope of code application. Under this trend of new opportunities, we can further use the functions of Chinese and Western codes to create and inherit the sustainability of bamboo furniture.

However, after the 1970s, due to the growing wealth of the Taiwanese people and changing consumer needs, the development of bamboo furniture style has changed from practical to decorative. Therefore, the use of codes in the design of furniture highlights its importance.

This research uses Chinese and Western literature review and data analysis to conduct research and adopts Liushu, the six methods of forming Chinese characters [12]. At the same time, referring to the graphic data of the Tang, Ming, and Qing Dynasties of China, we have analyzed and compared the similarities and differences between modern bamboo furniture and traditional bamboo tube furniture in the use of codes in decorative styles. After interviews with experts, we obtained the views of Taiwan's traditional and modern bamboo craftsmen on bamboo tube furniture application code making experience and design style, while also offering our practical experience, in order to verify the practical application of code theory and the importance of participating in decorative design and production. In the research process, we systematically integrated the Western scholar Saussure's (1906) "signified" and "signifier" thinking [13] into the creation of bamboo furniture, in addition to using the theory of synchronicity and diachronicity and the Umberto Eco code cited by Lin Minghuang (2000) [14]. We combined the functional code, emotional code, and communicational code proposed for product design with the "human nature identification code" proposed in this research, and these four codes were applied to the design process of bamboo furniture. The purpose of this research was to explore the decorative design of bamboo furniture with codes, apply the functions of codes, interpret the rich content of bamboo culture, understand the needs of the environment, provide and guide the new direction of bamboo furniture decoration design, and develop new bamboo-made products in Taiwan.

\section{Literature Discussion}

\subsection{Recognition, Thinking, and Application of Symbols and Codes}

Semiology was originally a concept proposed by French professor Ferdinand de Saussure (1857-1913). He regarded symbols as two-sided entities, which he referred to as "signifier" and "signified", He believed that in a cognitive system, symbols refer to images with a certain meaning and can be combined with concrete and abstract pictures and texts such as symbols, discourses, words, thoughts, time and space, affairs, and shapes [13].

Using the principle of the symbolic function (system) of Ernst Cassirer (1874-1945), we can also understand that art's purpose is to "discover" the world, that is, connotation and creativity [15].

\subsubsection{Code}

Based on the system application and combination of Saussure's semiology, a "code" is formed from cross-intergeneration. Umberto Eco [16] proposed technical codes, syntactic codes, and semantic codes for the meaning of symbols in architecture, while Lin Minghuang (2000) quoted Umberto Eco codes in "Symbols and Codes in Product Modeling" and proposed the following three levels of codes for product design: functional codes, emotional codes, and communicational codes [14]. A brief description of these three codes is as follows: (1) functional code is the cornerstone of the code system. Objects are perceived 
by their mobility and relevance in space, which is based on the common understanding of human beings. (2) Emotional code indicates that the impact on the object depends on the emotional level of the user's heart, most of which exists in symbolic signs and image signs. (3) Communicational code hints at inner feelings and is about the transmission of information; the product wants to tell stories, legends, philosophical thoughts, etc. On the other hand, Lin Minghuang also mentioned, "It is assumed that code is the smallest unit that governs the characteristics of a single sign. The theory of semiotics is widely used in modern design and has produced significant effects" [17].

\subsubsection{Thinking and Application of Human Nature Identification Code}

The aforementioned three levels of functional code, emotional code, and communicational code have meaning and effectiveness at each level. However, in this era of rapid changes in modern time and space and technological advancement, the three codes do not mention how to identify various objects at the level of functional codes and their operations in space and nature. The emotional code level must have methods to express the images of various objects that users want. The communicational code level must have methods to choose products and communicate and express their feelings. Therefore, this research aimed to use the "human nature identification code" to reinforce the role of the three-level code and was oriented towards integrating wisdom and emphasizing the understanding of human feelings and expectations with human nature, in order to distinguish right and wrong, true and false, as well as integrate people, events, objects, time, and space to select and apply codes. For example, to make and design a bamboo art product that meets the needs of modern consumers, in addition to considering the functionality of the material, structure, decoration, combination, and form, it is also necessary to know the user's psychological and physical needs. Furthermore, some method needs to be adopted to inform users of the excellent characteristics of bamboo products. Finally, the "human nature identification code" must have methods to introduce the essence of humanity between users, designers, and producers to identify, select, and apply appropriate codes, develop the most harmonious products, and complete the transaction, thus complying with the vision of human life in the 21st century.

\section{Identifier definition and identifier meaning}

An "identifier" is a name that identifies (that is, labels the identity of) either a unique object or a unique class of objects. The abbreviation ID often refers to identity, identification (the process of identifying), or an identifier (that is, an instance of identification). An identifier may be a word, number, letter, symbol, or any combination of those [18]. With regard to "integrated identification technologies," such as proximity cards, the radio frequency signal (RF) is used to send and receive identification codes. This is science and technology, without life, humanity, or nature [19].

2. Human identification and humanity nature identification:

Jindrich Kodl believes that human identification is a practical matter. In various contexts, each of us needs to identify other individuals in order to conduct a conversation or transact business. Furthermore, multi-purpose identification schemes have led to an assessment of public policy issues arising from human identification [20]. His article applies physical and scientific methods to discuss human identification. In this study, we use humanity nature and humanity as the starting point for discussing humanity nature identification and their different application methods.

3. Application of human nature identification code

Entering the 21st century, an era of technological advancement, diversified knowledge integration, and a sharp increase in quality, the famous Japanese architect Kengo Kuma designed the human nature identification code to fully express the architectural philosophy from "space" to "time". In his representative work "Negative Architecture", the Great Bamboo Wall 2002 at the Great Wall in Beijing, he advocated negative architecture. In 
this context, "negative" means passive, that is, the concept of "fusion", in which the design is not better than the surrounding environment but merges with the surrounding environment. This is the "negative theory of fusion" [21].

\subsubsection{The Liushu Code of Chinese Culture and the Discussion of Western Code}

As far as Chinese culture is concerned, "Shuowen Jiezi", abbreviated "Shuowen," is the first Chinese dictionary and was edited by Xu Shen in the Eastern Han Dynasty (30-124 AD). With a total of 9353 characters, it serves as a reference book of Chinese characters [13]. The theory of Liushu (six categories of Chinese characters) was first used to analyze the structure of Chinese characters, explain the meanings based on the shapes, and seek the source based on the sounds. It is an important reference book for people to understand and master ancient pronunciation and vocabulary and be able to read through the ancient books of the pre-Qin and Han [22]. "Liushu" refers to the six structural regulations of Chinese characters, including pictograms, significants, pictographs, pictophones, re-annotations, and phony combinations, all implying the use of four codes. According to Saussure's classification of symbol theory, pictograms and pictophones can be considered the "signifier" of symbols, while re-annotations and phony combinations can be considered the "signified" in the symbol. The meaning of "pictophones" is a combination of "graphic symbols" and "sound symbols". Such "pictophone" characters account for $90 \%$ of Chinese characters. In the "Liushu" "graphic symbols" are used to represent the category of meaning and "phonetic symbols" to represent the categories of sounds, which were recorded by the combination of life language and things. Compared with Saussure's thinking (1857), "language" is regarded as a "symbol system", which includes the signifier (phonetic pattern) and signified (connotation). Therefore, Chinese and Western codes can both be applied. Theoretically, the content is similar, but the origin of culture differs in time and space. Whether a personal or general decoration design, craftsmanship has always had an interactive and harmonious relationship with its form and content. Therefore, this research explored how the theme became the content of the work through the use of various codes.

As seen from the above, the various theories of Chinese and Western codes have been important for creating works. Since the design and aesthetic relationship of works can be presented by different codes, this is the basic value of a work [23]. Nevertheless, various scholars have had quite different opinions on codes, which are organized in Table 1 for summary and collation.

Based on the systematic application and combination of Saussure's semiology [4], this study organizes and summarizes the results from each scholar's discussion of codes in Table 1 and provides them in Table 2.

In Table 2, we have summarized related factors, such as time, space, form (signifier), content (referent), etc., based on the aforementioned structure and connotation of the codes, showing that both Chinese and Western scholars have their own point of view in the background and constituent factors of codes. Synthesizing these viewpoints and applying them to the practice of bamboo furniture decoration art can prove the necessity of applying codes, which is explained in the next section. 
Table 1. Summary of the Interpretations of Chinese and Western scholars on symbol codes (compiled in this research).

\begin{tabular}{|c|c|c|}
\hline Scholar (Year) & Interpretation of Symbol Codes & Description \\
\hline 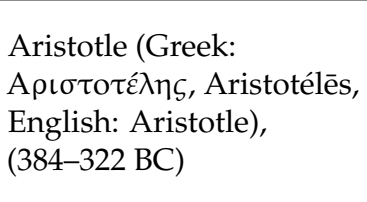 & $\begin{array}{l}\text { Words are the signs and representations of the } \\
\text { mental process, as well as the signs and } \\
\text { representations of speech. }\end{array}$ & $\begin{array}{l}\text { All people do not have the same word mark, and } \\
\text { all people do not have the same voice, but the } \\
\text { spiritual processes directly implied by these } \\
\text { words are the same for all people, in the } \\
\text { "Explanation On Tools". }\end{array}$ \\
\hline
\end{tabular}

\begin{tabular}{l} 
Hippocrates \\
(Ancient Greek: $\pi \pi \mathrm{o \kappa \rho \alpha ́} \tau \eta \zeta$, \\
$460-370 \mathrm{BC}$ ) \\
\hline
\end{tabular}

People's facial expressions, mental states, etc., are considered to be symbolic phenomena; they are symbols of human health.

The experience gained from clinical observation of patients is explained by "semiology."

\section{Simonides (556-468 BC)}

Put forward "painting is silent poetry, poetry is

\begin{tabular}{ll}
\hline John Locke (1632-1714) & Representation of an idea. \\
\hline $\begin{array}{l}\text { Immanuel Kant } \\
\text { (1724-1804) }\end{array}$ & $\begin{array}{l}\text { The signs are divided into three types: } \\
\text { arbitrary (artistic), natural, and miraculous. } \\
\text { Points out the concept contained in the symbol. }\end{array}$ \\
\end{tabular}

\section{Charles Sanders Peirce (1839-1914)}

Ferdinand de Saussure (1857-1913)

\section{Ernst Cassirer (1874-1945)}

$$
\begin{aligned}
& \text { "Symbol" is } \\
& \text { to another. }
\end{aligned}
$$

All experiences and thoughts are symbolic activities. Symbols can be divided into three categories: icon, index, and symbol.

Proposes that language is a sign system. A whole composed of two parts of the signifier and the signified is called a symbol. there. Sound painting." When differences between poetry and painting are found, the symbols used by them are different.

It shows that calligraphy and painting are interconnected.

Links symbols with humans.

The proposition that "all languages are signs of thought" is the continuation and development of semiotic thought; the second principle connects signs and concepts.

The endless theory of symbolic function, especially from the perspective of how to understand visual artworks, is more applicable than Saussure's binary symbol structure.

Signs can be divided into "signifier" (the sound and image of the symbol) and "signified", which have a mutual relationship.

The principle of symbolic function (system) is universal, effective, and comprehensive. It opens the door to the special cultural world of mankind. "Semiotic Aesthetics" is based on "simulation theory", and art should be the "discovery" (not imitation) of the world.

Codes are two-sided bodies that combine content and expression, while elements are only one-sided bodies. The elements of content form and expression form can be combined into codes with both content and expression through "conversion".

"essence" is outside the language that reflects the form entity.

It is the mixture of a denoted component (signifier) and a denoted component (implication). The symbol system is divided into three parts: (1) signifier and implication; (2) horizontal combination system; (3) original implication and extended implication.

Codes actually have two levels of meaning. The first level is meaningless codes, that is, the phenomena emitted by the codes themselves and that follow the meaning. Therefore, the second level of symbolic meaning is the meaningful symbols that follow the operation of the codes.

Current President of the International Semiotics Association. 
Table 1. Cont.

\begin{tabular}{|c|c|c|}
\hline Scholar (Year) & Interpretation of Symbol Codes & Description \\
\hline $\begin{array}{l}\text { Zhouyi (approximately } 770 \\
\text { BC in the Western Zhou } \\
\text { Dynasty), Fuxi made the } \\
\text { hexagram, the king of Wen } \\
\text { wrote the text, and } \\
\text { Confucius made the } \\
\text { ten wings }\end{array}$ & $\begin{array}{l}\text { The origin of Chinese philosophy laid down } \\
\text { some basic categories of Chinese philosophy, } \\
\text { with a total of } 64 \text { hexagrams and } 384 \text { lines. }\end{array}$ & $\begin{array}{l}\text { Such concepts as "yin and yang" have had a } \\
\text { great influence on the Chinese people. So far, } \\
\text { academic masters to fortune tellers in the streets } \\
\text { regard it as the canon and have made deep } \\
\text { research. }\end{array}$ \\
\hline $\begin{array}{l}\text { Liushu (Xu Shen in Eastern } \\
\text { Han Dynasty) } \\
\text { (approximately 58-147 AD) }\end{array}$ & $\begin{array}{l}\text { Compilation of a book of Wen Jiezi, pictograms, } \\
\text { significants, pictophones, pictographs, } \\
\text { re-annotations, and phony combinations are } \\
\text { the earliest applications of symbols and codes } \\
\text { in China. }\end{array}$ & $\begin{array}{l}\text { Among them, pictograms, significants, } \\
\text { pictophones, and pictographs are mainly } \\
\text { "character creation", while re-annotation and } \\
\text { phony combinations are "character application"; } \\
9353 \text { characters were included. }\end{array}$ \\
\hline Su Shi (1279) & $\begin{array}{l}\text { In the On Mojie Lan Tian Painting, it says, } \\
\text { "When appreciating the poems of Mojie, there } \\
\text { are pictures in the poems, and poems in the } \\
\text { pictures." It is the communication code } \\
\text { between image and text. }\end{array}$ & $\begin{array}{l}\text { Similar to Simonides' theory, it implies the } \\
\text { correlation of codes between images and texts. }\end{array}$ \\
\hline $\begin{array}{l}\text { Dictionary of } \\
\text { Education (2000) }\end{array}$ & $\begin{array}{l}\text { Cultural code is the deep structure of a } \\
\text { society's culture, the action system of personal } \\
\text { life. }\end{array}$ & The interactive performance of life and culture. \\
\hline
\end{tabular}

Table 2. Summary of the structure and connotation of codes (compiled in this research).

\begin{tabular}{|c|c|c|c|}
\hline Factor & Dimension & Connotations & Scholar (Age) \\
\hline & Time & $\begin{array}{l}\text { Process, experience, transformation, extension, } \\
\text { communication, transformation, etc. }\end{array}$ & $\begin{array}{l}\text { Ernst Cassirer,1874; Su Shi (1279); Dictionary } \\
\text { of Education (2000) }\end{array}$ \\
\hline $\begin{array}{l}\text { Background } \\
\text { factor }\end{array}$ & Space & $\begin{array}{l}\text { Individualism, development, } \\
\text { interaction/operation/communication, world, } \\
\text { universal/comprehensive/two- } \\
\text { sided/horizontal combination, culture, form, } \\
\text { human, society, environment, life, } \\
\text { independence, etc. }\end{array}$ & $\begin{array}{l}\text { The Book of Changes (770 BC); John Locke } \\
\text { (1632-1714); Ernst Cassirer (1874); Louis } \\
\text { Hjelmslev (1899); Roland Barthes (1915); } \\
\text { Dictionary of Education (2000) }\end{array}$ \\
\hline \multirow[b]{2}{*}{$\begin{array}{l}\text { Composition } \\
\text { factor }\end{array}$} & $\begin{array}{l}\text { Form } \\
\text { (signifier) }\end{array}$ & \multicolumn{2}{|c|}{$\begin{array}{l}\text { Characterization/shape/form/image/pictogram/representation/4 BC); Xu Shen (58 AD); } \\
\text { phenomenon, expression, structure, composition, } \\
\begin{array}{ll}\text { mixture, material, technology/technology, model, } & \text { Hippocrates (460 BC); Simonides (556 BC); } \\
\text { mark/logo/symbol, feature, image, work, } & \text { Su Shi (1279); Kant (1724); Pierce (1739); } \\
\text { inheritance, mark, recognition, etc. } & \text { Saussure (1857); Roland Barthes (1915) }\end{array}\end{array}$} \\
\hline & $\begin{array}{l}\text { Content } \\
\text { (signified) }\end{array}$ & $\begin{array}{l}\text { Mind process, spirit, idea/concept/thought, } \\
\text { sign/symbol/referent, in } \\
\text { tercommunication/connection/relationship, } \\
\text { effectiveness, value, system, application, culture, } \\
\text { art, science, philosophy, creativity, meaning, } \\
\text { pictograph/instruction/re-annotation/phony, } \\
\text { definition/etc. }\end{array}$ & $\begin{array}{l}\text { Aristotle (384 BC); Xu Shen (58 AD); } \\
\text { Hippocrates (460 BC); Simonides (556 BC); } \\
\text { Su Shi (1279); Kant (1724); Pierce (1739); } \\
\text { Saussure (1857); Roland Barthes (1915) }\end{array}$ \\
\hline
\end{tabular}

\subsection{Bamboo Tube Furniture Decoration and Code}

\subsubsection{The Codes of Chinese Bamboo Tube Furniture}

Chinese-style furniture uses bamboo and wood as its main materials, which have been used for over five thousand years. Due to the differences in political conditions, humanities, and folk customs in the past Chinese dynasties, as well as the natural rhythms, the "shape" and "connotation" of furniture in life have been affected, that is, the Western "signifier" and "signified". 
Bamboo furniture in the Ming and Qing Dynasties was not noticed by people, insomuch as it had no special introduction. The main reason is that bamboo furniture was cheap and easy to obtain, as well as difficult to preserve for a long time. A watercolor sketch of a Chinese bamboo furniture store painted by the British in the early 19th century (Figure 1) [23] and illustrations of the engraved "Jade Hairpin" in the Wanli period of the Ming Dynasty and the bamboo couch in the woodcut illustration of "Flounder" in the Qing Dynasty (Figure 2) [24] all show that bamboo furniture was very mature at that time and was an indispensable artifact in life and culture.

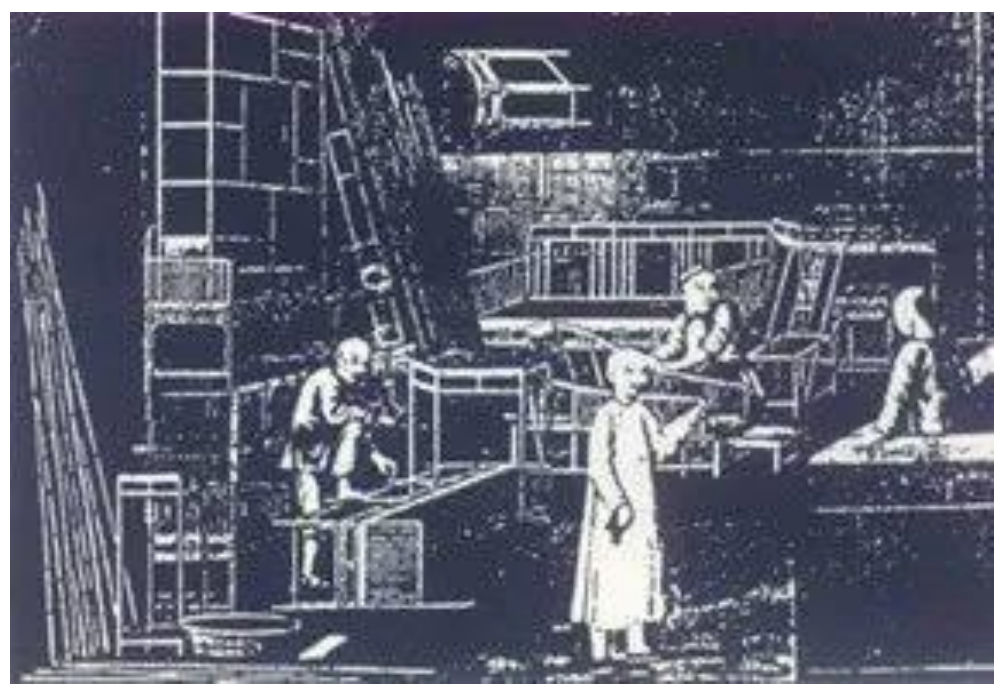

Figure 1. Bamboo furniture store.

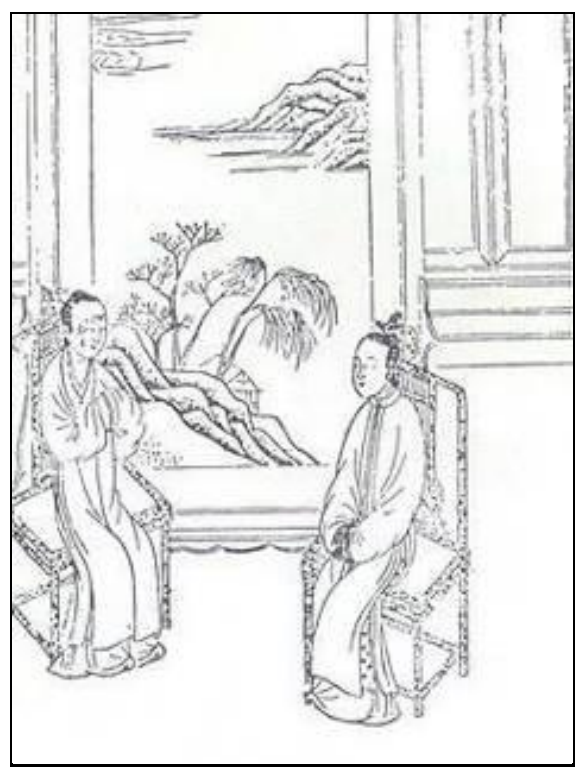

Figure 2. Jade Hairpin and Flounder.

For example, the seven sages of the bamboo forest in the Wei and Jin Dynasties and the poetry of the Tang and Song Dynasties show a special preference for bamboo. The instances of literature discussing bamboo life utensils are too numerous to mention. According to Cao Xueqin's works of Dream of Red Mansions in the Qing Dynasty, more than 150 codes of life culture are related to bamboo throughout the entire book, such as the use of "shou" in bamboo decorations (Figure 3). 


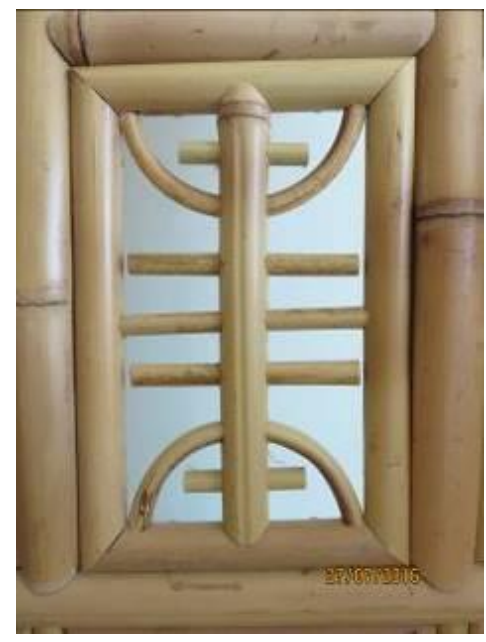

Figure 3. "Shou" character.

\subsubsection{Taiwan Bamboo Tube Furniture and Codes}

"Bamboo" is an indispensable material in the lives of Taiwanese ancestors and has become a particularly good material under the gradual emphasis of environmental protection in the 20th century. Lian [25] said in Taiwan General History, "Taiwan's bamboo craftsmanship is a bed, a table, a basket. Daily utensils are available everywhere", such as bamboo steamer, etc. The preparation of fine bamboo craftsmanship is a sideline of rural women's slack time, and the "chiseling" of large-scale bamboo furniture comes from the craftsmanship of men [15]. As time passed, the style gradually changed from the tradition of Fujian and Guangdong to life bamboo art products with inherent characteristics of Taiwan. This separation of time and region has naturally had its own uniqueness in the evolution of cultural codes. In 1943, Japanese folk art scientist Liu Zongyue came to Taiwan for investigation. He especially appreciated the natural beauty deeply rooted in rural life and highly evaluated Taiwan's traditional bamboo artists [26]. For example, the "brain" placed horizontally on the top of the chair of the bamboo tube Master is called "Niu Dan" (Figure 4). The symbol and meaning of its cultural code is: although the uppermost person has great power, he also shoulders great responsibility.

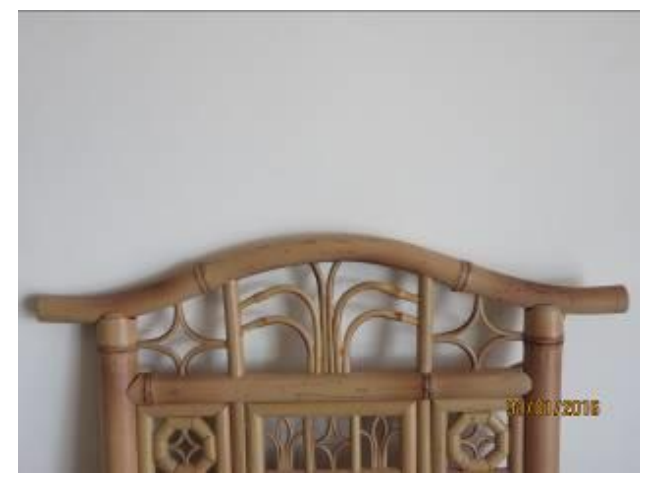

Figure 4. Niu Dan.

In the 1970s, Taiwan's economy took off, and living standards improved significantly. Among the increasing importance to the application of environmentally friendly materials, the design and production of bamboo tube furniture in Taiwan has moved towards exquisite decorative works and have gradually become art collections (Figures 5-7) [27]. Therefore, Taiwan's bamboo tube seats have gradually shown local, cultural, and economic characteristics of literary codes. 


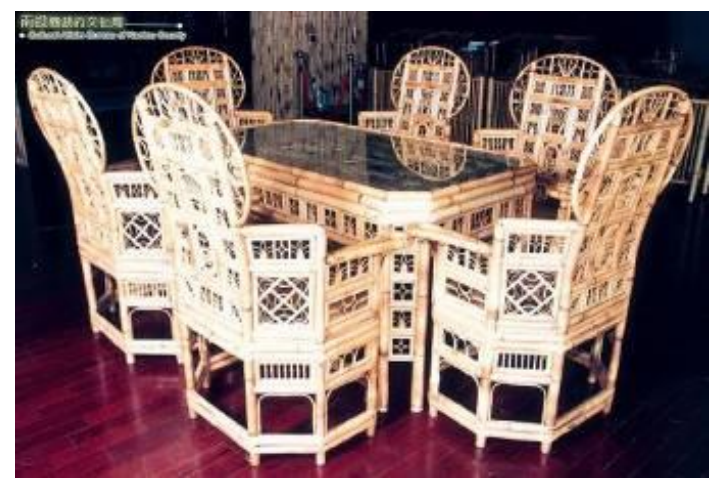

Figure 5. Bamboo art collection.

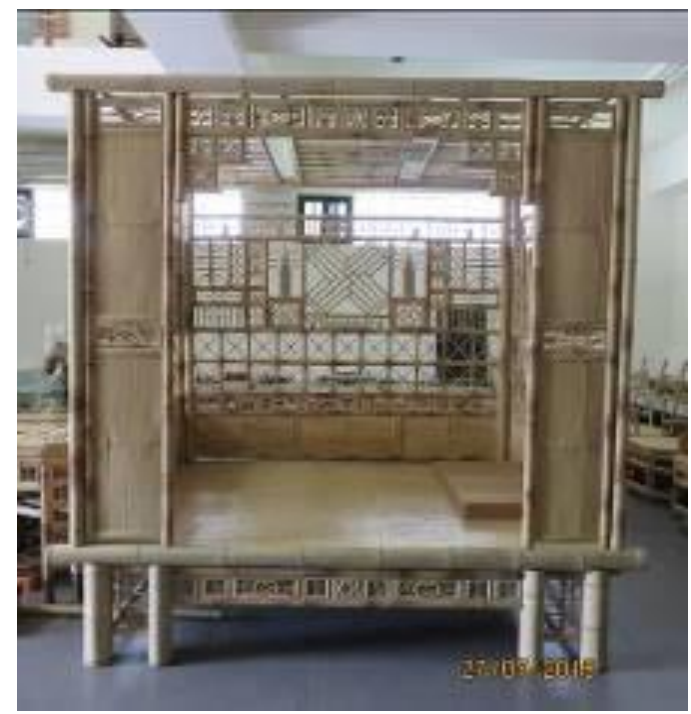

Figure 6. Bamboo art collection.

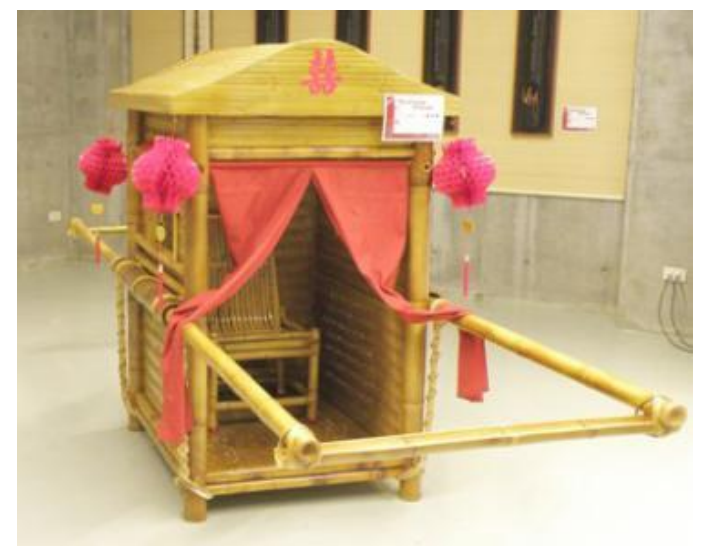

Figure 7. Bamboo sedan chair for marriage.

\section{Research Method}

Regarding style, Western scholars generally believe that the study of style is to explore the similarities and differences between various works, that is, the universality and uniqueness of styles, while paradigmization is a general research method [8]. The purpose of this research was to use the signifier and signified functions of the code, as well as the six types of codes and the functions of "concrete", "abstract", "single body", and "combined body" 
to explore the unique decorative design style of bamboo tube furniture. Therefore, this research has primarily used the three research methods of literature content analysis, expert interviews, and participatory action research (PAR). Four types of codes, namely, functional codes, emotional codes, communicational codes, and human identification codes, were used as research tools and to make the bamboo master chair to complete the research.

\subsection{Research Objects, Scope, and Limitations}

The object of this research was bamboo tube furniture seats. The early use of bamboo seats in Taiwan can be roughly divided into three types [28]: (1) Ming-style in Fujian and Guangzhou, such as the master chair, washbasin stand, flower stand, thorn bamboo stand, recliner, bamboo stool, etc.; (2) life application type, such as a bamboo table, bamboo chair, bamboo bed, bamboo stool, nursing mother chair, baby-carriage, bamboo cabinet, bamboo frame, bamboo steamer, etc.; (3) creation artistic styles, such as emperor chair, mandarin duck pillow, baby stroller, etc. Due to the various categories and titles of bamboo tube furniture, collecting all kinds of furniture is difficult [16]. Furthermore, in order to distinguish between the general style and unique style of bamboo chairs, this research has approached the actual research object to facilitate the induction and analysis. The research scope is limited to the bamboo tube armrest seat, and the artistic creation of the "emperor chair" was selected. The "empress chair" is the scope of code application. As for other stools, tables, and chairs, we are limited by space and have not included them in the discussion and analysis of this paper.

The collection of data in this research is limited by the difficulty of obtaining firsthand information, so we used second-hand published books and literature for analysis. For example, we referred to Li Zanshou's book "Bamboo Ware for Taiwan Residents in the 20th Century," Yan Shuilong's book "Taiwan Crafts," and Liu Zongyue's book "Artistic Aesthetics." Secondly, due to the scarcity of historical objects and the limited information obtained from the literature, pictures and texts, and traditional master's handed down bamboo tube furniture works, it is not appropriate to rashly affirm them as a new development of early Han culture, even if they developed and changed into Taiwan's bamboo tube furniture [16]. Currently, the remaining available samples have no sampling function and significance [29], so the "representation" and "model" of the samples in this study may inevitably be questioned, thus demonstrating the limitations of the content analysis method [30].

In terms of quantity analysis, due to the limitation of pictures of bamboo chairs actually available, this research could not perform general quantitative analysis and thus used expert interviews and action research to supplement the research deficiencies to help understand the phenomenon.

\subsection{Data Collection and Analysis}

The collection of the research materials is based on the application and research of the connotation of the combination of "shape" and "meaning" in the Liushu of Chinese culture in the literature. In terms of the physical collection, since bamboo is easy to obtain and perishes, keeping and preserving bamboo furniture is difficult. Only the oral data and existing furniture obtained from interviews with eight famous traditional bamboo furniture stores in Taiwan have been used as first-hand information.

\section{Results and Analysis}

This research primarily adopted the content of the literature to recognize the meaning of codes. Through expert interviews, we were able to obtain the insights and experiences of traditional craftsmen and modern craftsmen experts on the application of codes. In addition, with more than 20 years of experience in bamboo handicrafts, we used functional codes, emotional codes, communicational codes, and human identification codes as tools, and the code combination of "shape" and "meaning" in the "Liushu" as resources, in order to apply them to the decorative design of bamboo tube furniture. Therefore, we conducted 
participatory action research (PAR) to make bamboo "emperor chairs" and "empress chairs" to verify the correlation between codes and bamboo furniture decoration design.

\subsection{The Meaning of Codes}

4.1.1. Comparison of Design Component Names of Chinese-Style Wooden Master Chair and Bamboo Tube Master Chair

First, we have explained the appearance of the traditional Chinese wooden chair and the bamboo tube chair to define the comparison names of the various components of the chair to facilitate subsequent analysis and research (Figure 8). In the Figure 8, the names from top to bottom are as follows: (1) top pole; (2) back plate; (3) handrail; (4) federal stick; (5) decoration; (6) cushion; (7) waist; (8) legs; and (9) foot pole.

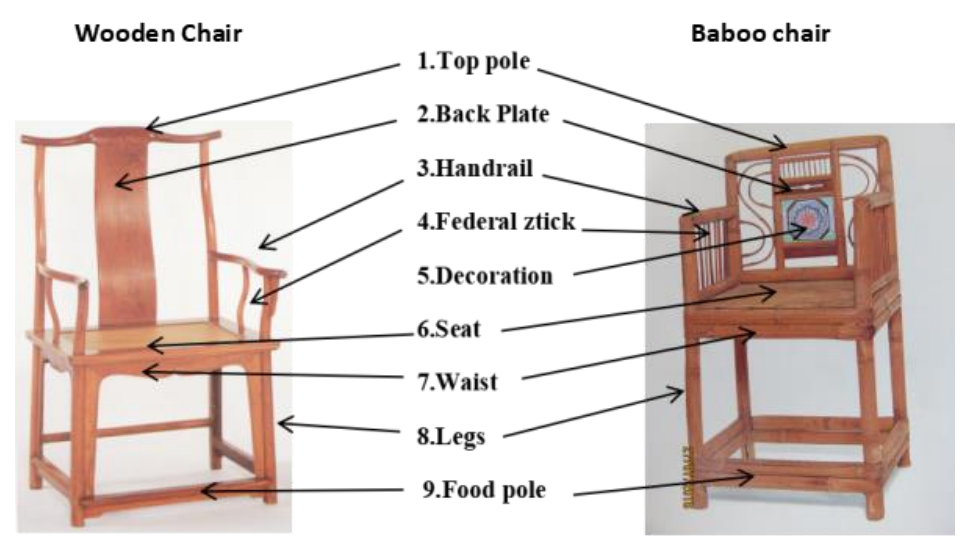

Figure 8. Appearance name comparison of Chinese-style wooden master chair and.bamboo tube master chair.

Then, this research selected three styles that represent modern Taiwanese bamboo tube master chairs as samples (Figures 9-11), applied codes to explore the decorative design of bamboo tube furniture, and compiled and linked relevant codes for comparison, analysis, and explanation, as shown in Table 3.

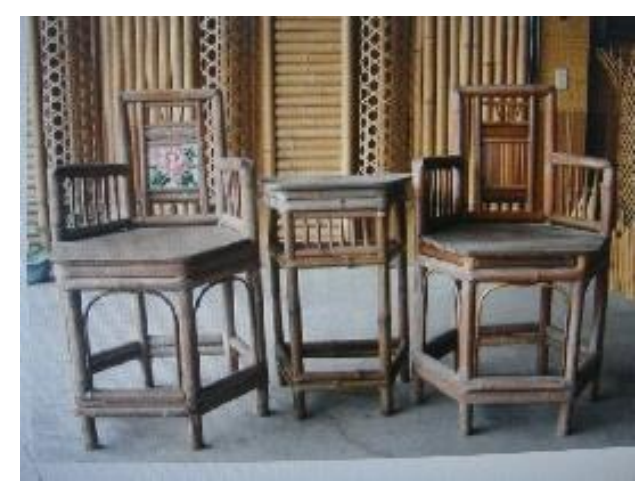

Figure 9. Bamboo Master Chair(1). 


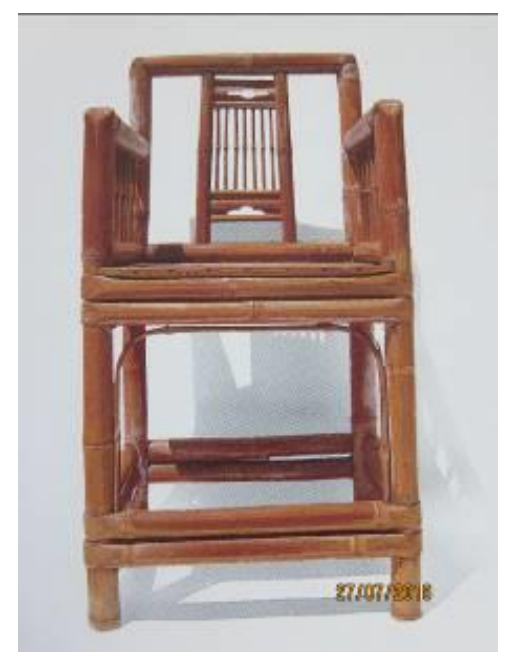

Figure 10. Bamboo Master Chair(2).

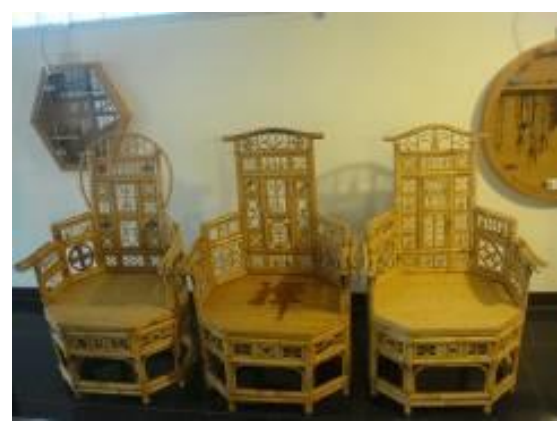

Figure 11. Bamboo Master Chair(3).

Table 3. Comparison of the styles of bamboo tube chairs and Chinese and Western codes.

\begin{tabular}{|c|c|c|c|c|c|}
\hline Material & & & Bamboo & & \\
\hline Type & & “Taiwa & le" Bamboo Tub & Iaster Chair & \\
\hline Age & \multicolumn{2}{|c|}{ 1912-2014 } & 1961-2014 & Western Codes & Liushu Codes \\
\hline \multirow[b]{2}{*}{ Picture } & \multirow{2}{*}{ Simple type A } & Simple type B & Gorgeous type & \multirow[b]{2}{*}{$\begin{array}{l}\text { A. Functional code, } \\
\text { B. Emotional code, } \\
\text { C. Communicational } \\
\text { code, } \\
\text { D. Human nature } \\
\text { identification code }\end{array}$} & \multirow[b]{2}{*}{$\begin{array}{l}\text { a. Pictogram, } \\
\text { b. Instruction, } \\
\text { c. Pictograph, } \\
\text { d. Pictophone }\end{array}$} \\
\hline & & & apd $=1$ & & \\
\hline Top pole & $\begin{array}{l}\text { Horizontal-lead } \\
\text { angle type }\end{array}$ & Official hat type & Hump type & A, B, C & $a, c$ \\
\hline Back plate & Panel mixed type & Grid type & Grid type & $A, B, C, D$ & $a, b, c$, \\
\hline Handrail & $\begin{array}{l}\text { Straight and flat } \\
\text { type }\end{array}$ & Arc & $\begin{array}{l}\text { Forward } \\
\text { protruding }\end{array}$ & $\mathrm{A}, \mathrm{B}, \mathrm{C}$ & $a, b, c$, \\
\hline Federal stick & $\begin{array}{l}\text { Multi-pendant } \\
\text { type }\end{array}$ & Grid type & Grid type & $\mathrm{B}, \mathrm{C}$ & $a, b$, \\
\hline
\end{tabular}


Table 3. Cont

\begin{tabular}{|c|c|c|c|c|c|}
\hline Material & \multicolumn{5}{|c|}{ Bamboo } \\
\hline Type & \multicolumn{5}{|c|}{ “Taiwan style” Bamboo Tube Master Chair } \\
\hline Age & \multicolumn{2}{|c|}{ 1912-2014 } & 1961-2014 & Western Codes & Liushu Codes \\
\hline Decoration & Mosaic decoration & Add curved strips & $\begin{array}{l}\text { Inlaid + baked } \\
\text { decoration }\end{array}$ & $A, B, C, D$ & $a, b, c, d$ \\
\hline Cushion & Square & Polygon & Polygon & $\mathrm{A}, \mathrm{B}, \mathrm{C}, \mathrm{D}$ & $a, b, c$ \\
\hline $\begin{array}{l}\text { Waist (below the } \\
\text { cushion) }\end{array}$ & Parallel & Empty + Parallel & Empty + Parallel & $A, B, C, D$ & $a, b$, \\
\hline Legs & Round tube & Round tube & Round tube & $\mathrm{A}, \mathrm{B}, \mathrm{C}$ & $a, b$ \\
\hline Foot pole & Round tube & Round tube & Round tube & A, B, C, & $a, b$ \\
\hline $\begin{array}{l}\text { Combination } \\
\text { method }\end{array}$ & $\begin{array}{l}\text { Joggle joint + tube } \\
\text { wiping }\end{array}$ & $\begin{array}{l}\text { Joggle joint + tube } \\
\text { wiping }\end{array}$ & $\begin{array}{l}\text { Joggle joint + tube } \\
\text { wiping }\end{array}$ & A, & $a, b, c, d$ \\
\hline
\end{tabular}

4.1.2. The Application of Chinese and Western Codes in the Material, Structure, Decoration, and Combination Presents the Meaning of Bamboo Furniture

Based on the comparison of the design styles of the above bamboo chair components, we found that in terms of material, structure, decoration, combination, and style, the nine parts of each style of master chair show the connotation of functional code (A), emotional code (B), communicational code and (C), human identification code (D), and also contains the display of the four symbols in the "Liushu": (a) pictogram, (b) instruction, (c) pictograph, and (d) pictophone. These are described as follows:

(1) Material aspect: According to the report on the implementation results of the "Bamboo Industry Transformation and Revitalization Project" issued by the Agricultural Committee of Taiwan's Executive Yuan in December 2002 (No. 126), the total area of bamboo forests in the world is about 22 million hectares, $85 \%$ of which are located in Asia; six types of economic bamboo are common in Taiwan which cover an area of 75,275 hectares, of which, Osmanthus fragrans accounts for the largest $(52.53 \%)$, followed by Hemp bamboo (24.11\%), thorny bamboo (10.64\%), long-branch bamboo $(4.92 \%)$, green bamboo $(4.75 \%)$, and Mengzong bamboo (3.05\%), At present, the area of bamboo forest in Taiwan is estimated to be more than 200,000 hectares, accounting for half of Taiwan's artificial forestation area. It is a renewable resource with economic production scale and high availability. The bamboo forest has a large amount of carbon dioxide storage, which is worthy of attention to the effect of carbon reduction. In addition, Osmanthus fragrans bamboo is of good quality and easy to get, it is the most commonly used material for bamboo furniture. The material will affect construction method and durability (A). Wooden master chairs often use high-density wood with good patterns, such as mahogany, cypress, wenge, and other trees that are at least many decades old. However, the bamboo grandmaster chair only needs four-year-old environmentally friendly bamboo material (A). The use of the tough texture of the bamboo skin, the artistic conception of the bamboo forest, and the special shape of the hollow of the bamboo joints $(A, a, d)$, as well as the philosophical significance of the poet's so-called bamboo fortitude and integrity $(B, C, b, c)$, are all apparent (Figure 11); composite media has become increasingly popular with modern designers (A). For example, the collocation and application of bamboo furniture and glazed beads increase the intuitive feeling and transmission effect of the five senses $(A, C, D)$ and enhances the quality of works, thus showing the function of Chinese and Western codes(Figures 12 and 13). 


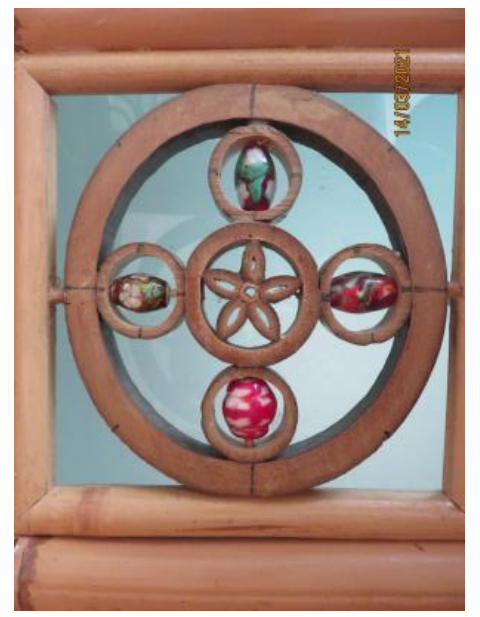

Figure 12. Bamboo furniture and glazed beads.

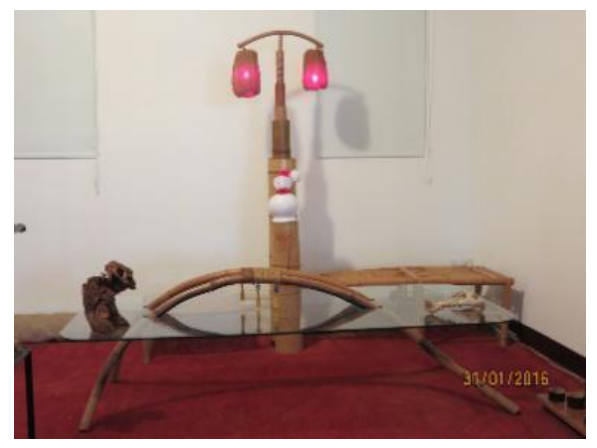

Figure 13. Feeling of five senses.

The design of bamboo furniture for steaming and cooking can also present and apply the meaning of various codes, such as the characteristics of bamboo steamers. The steamed food has the unique aroma of bamboo and wood, which is the secret of the delicious taste of many Taiwanese special snacks. In addition, the bamboo steamer has stories about history, culture, and local customs. The bamboo steamer is made by hand using bamboo and logs. For the steps (A, B, D, a, c, d) of bamboo splitting, planing, weaving, etc., choosing the material is especially important, one must choose 3-4 years old phyllostachys pubescen bamboo or Osmanthus bamboo and use its middle section $(\mathrm{A}, \mathrm{D}, \mathrm{a}, \mathrm{c})$

(2) Structural aspect: Structure is a support system for modeling and function. When the material affects the construction method, the construction method also affects the structure concept and change, an interactive effect of function transmission. For example, to make a bamboo master chair, a U-shaped tube (Figure 14) needs to be chiseled, and the main stem of the chair leg is clamped to make it fixed and durable. At the same time, the appearance of the clamped bamboo tube is smooth and beautiful, which makes the user happy and comfortable. Therefore, in addition to the function code, the emotional code, communicational code, and pictographic effect of Liushu are all shown. 


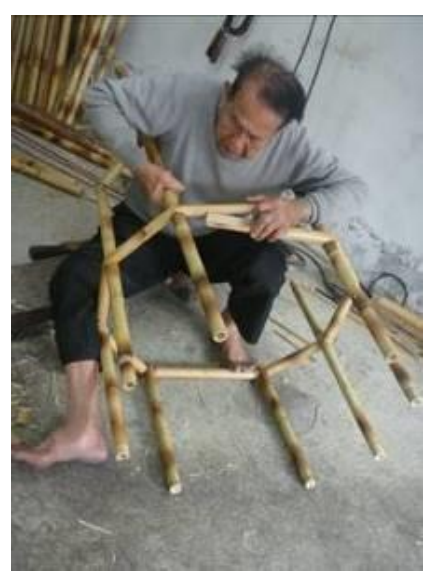

Figure 14. Tube wiping fixation method.

(3) Decoration: The purpose of decoration increases the effect of the functional code of material and structure, while also conveying visual beauty and style. The bamboo chair not only uses bake-curved inlay as its main decorative technique, but in the pattern shape, the decoration of the bamboo tube chair is mostly quoted in Chinese characters and auspicious totems, showing and integrating the interaction of codes.

(4) Assembled construction method: In the traditional Chinese wood construction method, "joggle joint" is an important technique and construction method, and bamboo products have also inherited this technique and construction method. However, the characteristic of the circular hollow section of the bamboo tube is that the method of "joggle joint and tube wiping" is the main technology and characteristic of the bamboo tube process, which has the function code and the Liushu pictographic effect, as shown in Figures 15 and 16.

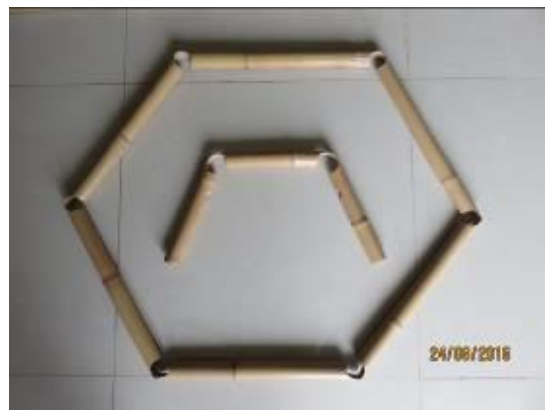

Figure 15. Octagonal panel card column method.

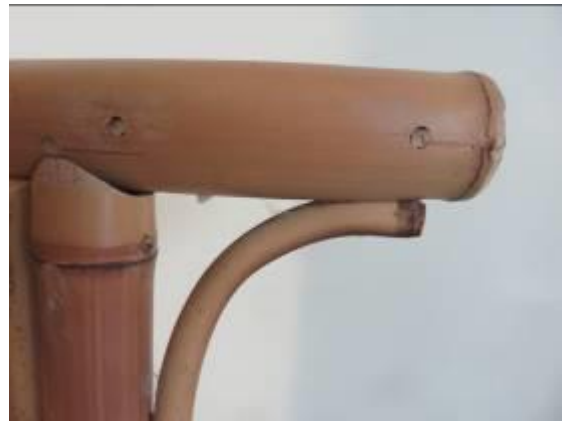

Figure 16. L angle fixing method. 
In the material, structure, decoration, and combination, the aforementioned Chinesestyle bamboo master chair shows the role of the functional code, the emotional code, the communicational code, and the identification code, as well as the four codes of Liushu. The relevance of the decoration design and the code has thus been verified.

\subsubsection{Expert Interviews and Application of Codes}

This research adopted the concept of codes to carry out "expert interviews." Eight Taiwanese traditional bamboo craftsmen and 11 contemporary craftsmen were visited to understand their views on the factors that influence the design style of traditional bamboo chairs, as well as provide their experience in furniture decoration design. In order to enhance the efficiency and focus of the interview, a semi-structured interview [30] was adopted, and the four elements of "form", "technology", "material", and "connotation" were used to make bamboo furniture the main items of the interview. Based on the expert interviews, we found that traditional bamboo craftsmen pay more attention to the application and performance of the function codes of the factors of "technology" and "material." In contrast, the modern craftsmen's application of codes for bamboo crafts focuses more on the expression of emotional codes, transmission codes, and human nature identification codes of the "type" and "connotation" factors.

\subsection{The Application and Experience of Chinese and Western Codes in the Production of the "Emperor Chair" and "Empress Chair"}

This research is based on the "emperor chair" developed by the bamboo artist Cheng Mingjia from Yunlin County, which has been passed on for three generations. In 1998, he was employed by the National Taiwan Craft Research and Development Center to teach the craft of bamboo furniture-making for many years. Relying on skills, ingenuity, design, and experience, the connotation of works, and the theory of codes, he became a famous bamboo craftsman in Taiwan. This research refers to the theory and function of Chinese and Western codes and has participated in the entire research process with 20 years of experience and practical actions, as well as integrated the development of the bamboo "emperor chair" and "empress chair". In order to enhance the effect and focus of the interview and analyze and explain the four aspects of "material", "technology", "form", and "connotation", we only use the two chair for the following interpretations and applications.

\subsubsection{Application of "Functional Codes" and Pictogram and Significant Codes in Liushu}

First, we used spaciousness, comfort, and classic simplicity as the main creative concepts for the production of the "emperor chair" and "empress chair." The application combination of functional codes and the four codes of Liushu were applied to the two seats. "Material" is based on natural and environmental protection, and bamboo patterns and bamboo joints have the dual functions of visual enjoyment. In terms of "technology", bamboo hollow tube wiping was used to ensure the technical function, and "form" is in the form of the pictographic "Eight-diagram", which has an auspicious meaning and makes the seat more spacious and stable. The fine decorations of the "connotation" pattern, such as the various auspicious patterns of the "backrest" (Figure 21), gives users the enjoyment of the five senses. Then, it was decorated with "pictograms" and "objects" drawn into figures, such as the "top pole" icon on the emperor's chair. The four-year-old bamboo shoots were roasted and bent into a "shoulder pole" shape to show the meaning of "responsibility", which is an abstract of the significant code. In this way, both Chinese and Western codes were used in the production of the "emperor chair" and "empress chair".

\subsubsection{Application of "Emotional Codes" and Significant and Pictograph Codes in Liushu}

The emotional code is more abstract and introverted, as is the significant code in Liushu, which emphasizes abstract content, while its impact on things focuses on the user's inner feelings and the symbolic communication between pictures and texts, such as Wang Wei's poems in painting and painting in poems. Bamboo is also frequently portrayed in Chinese painting; the artistic conception and spiritual reflection and feeling brought by 
bamboo in the sun differ from those of bamboo in the rain. Just like sitting on the bamboo pipe furniture "emperor chair" (Figure 17), it is cool and comfortable, and the feeling of the bamboo skin is delicate. The inlaid totem gives the user a natural, primitive, and precious feeling. Another example is the engraved totem "Zen" (Figure 18), back plate pattern (Figure 19) and the "empress chair" (Figure 20) engraved on the sitting board; the mellow totem and the inlaid glass beads give the user a feeling of tranquility and honor. Therefore, if the emotional code and the signifying and pictograph code have made some changes to the visual aspect, the perceiver should respond differently. The application of the two types of codes is related to "content".

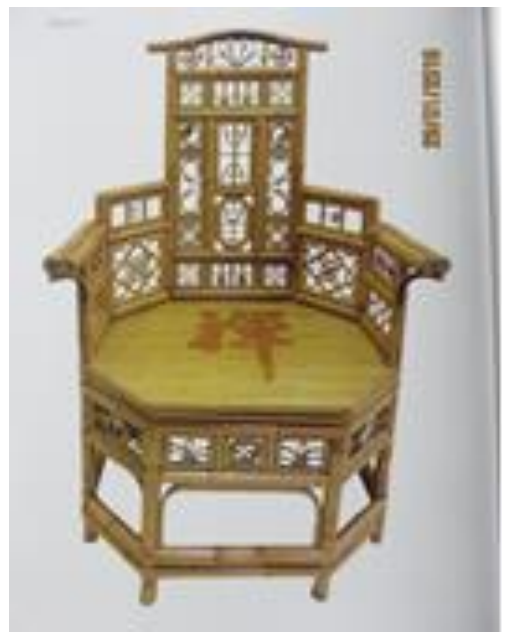

Figure 17. Emperor chair (The king's chair).

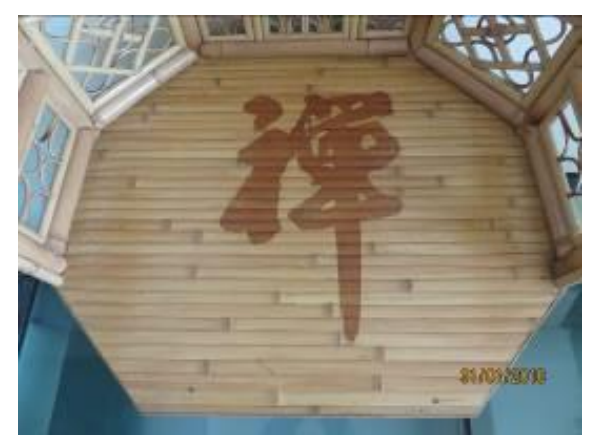

Figure 18. Octagonal seat surface's Zen character.The meaning of "sameness, tranquility, peace, worry, gain".

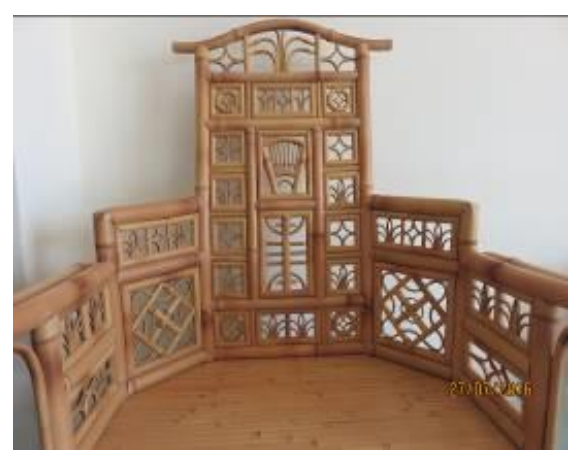

Figure 19. Back plate pattern decoration. 


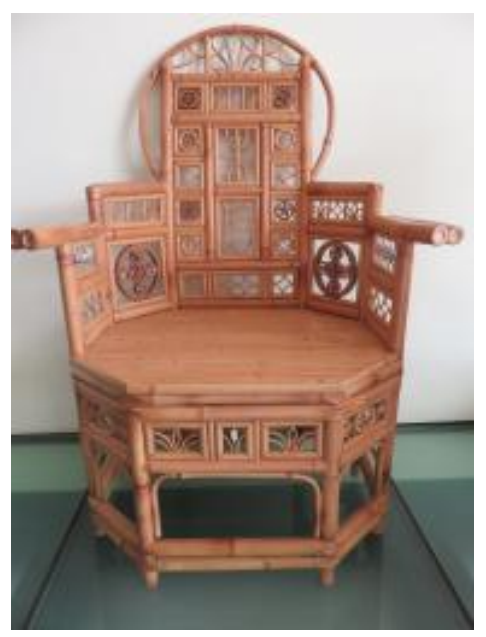

Figure 20. Empress chair.

\subsubsection{Application of "Communicational Codes" and Pictograph Codes in Liushu}

While emotional codes and significant codes imply superficial emotions, communicational code and pictograph code emotions in Liushu are combined into new ideas based on relations, which must be deep, far-reaching, and broad, mainly in the transmission of information, and in the customs, cultures, ideas, etc., that the product wants to express. All of these elements belong to the category of "communicational code" and "significant code." The designer will make the product portray the friendly human-machine interface. For example, the bamboo "emperor chair" (Figure 17) conveys the connotation of the shoulder pole for "responsibility", Yin and Yang for "infinity" (Figure 21), and Zen for "benevolent people and loving things." Furthermore, the user can feel that it is a lofty, noble, and gorgeous work from the bottom of their hearts. Therefore, combining this chair into a new idea according to its relations, using various codes, shows that it is not an ordinary chair, but can convey the context of the surrounding environment, which is the focus of production.

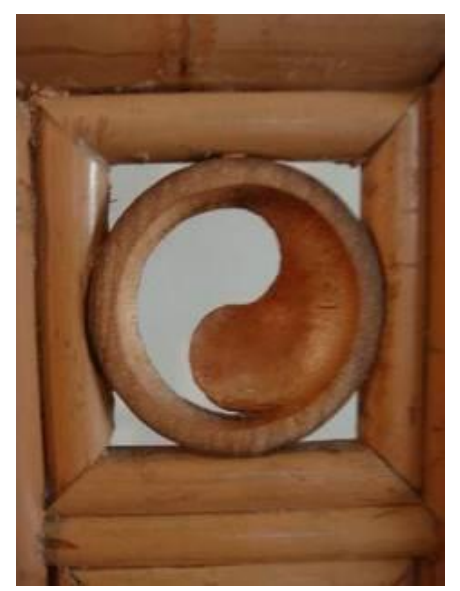

Figure 21. Yin and Yang.

4.2.4. Application of "Human Nature Identification Codes" and Pictogram, Significant, Pictograph, and Pictophone Codes of Liushu

In addition to comprehensively sorting out the application of the three codes and the six codes of the Liushu, this research refers to the concept of "negative architecture" and the connotation in Liushu applies the concepts of "tolerance" and "integration," injects the factors of mutual good and human nature, and builds an additional item of "human 
nature identification code" to integrate nature and human wisdom. For example, the round frame in the pattern of the empress chair (Figure 20) represents "tolerance and benevolence" (Figure 22), Fu Lu Shou Xi represents "auspiciousness" (Figures 23 and 24), flower blooming wealth and honor represents "people's wealth" (Figure 25), and auspicious figure ornaments and the use of a measuring ruler has the meaning of "Luban ruler". Particularly in the selection of environmentally friendly bamboo materials, when applied to decorative design, the style has returned to the natural and human nature of the "harmony of nature and man," which inspires future furniture creation.

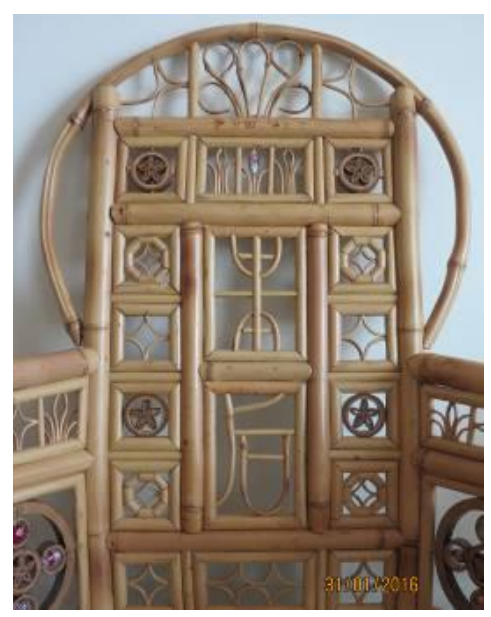

Figure 22. Round frame.

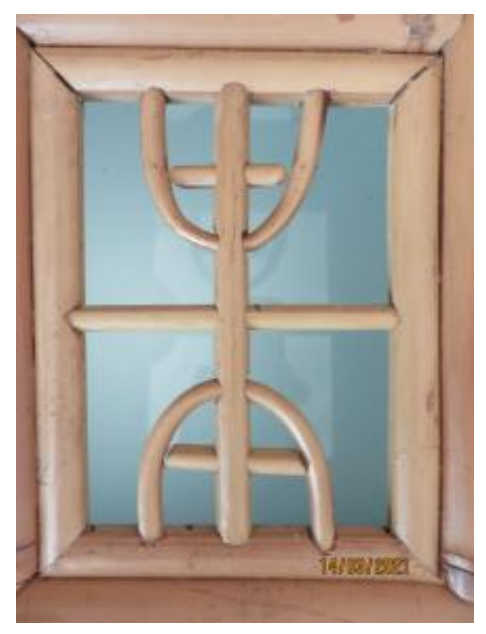

Figure 23. Shou (longevity).

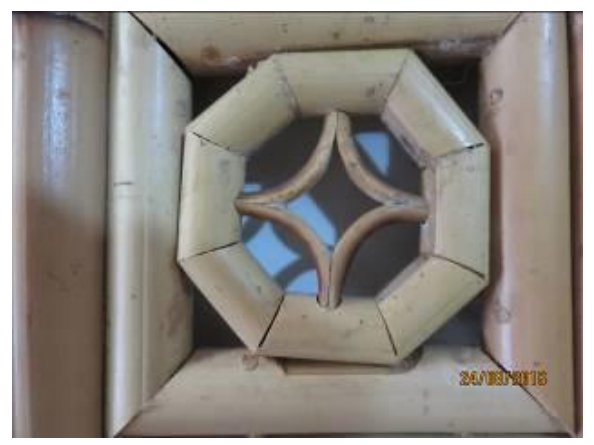

Figure 24. Wealth and power. 


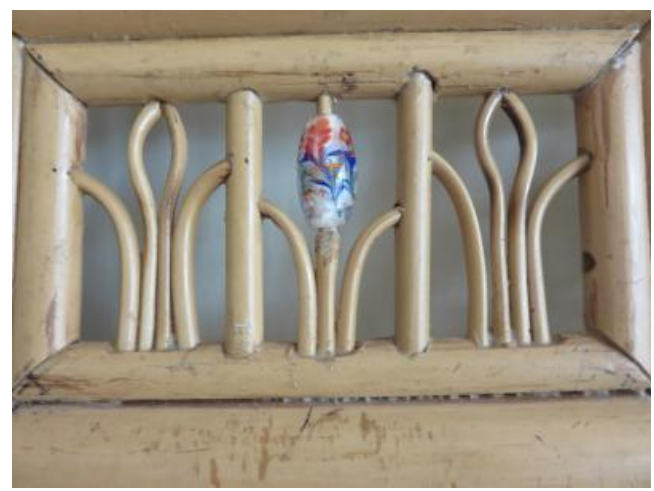

Figure 25. Flower blooming wealth.

\section{Conclusions}

In this study, we found that the application of Chinese and Western codes affects the decorative design style of bamboo furniture. With regard to the effects of the decorative design of bamboo furniture, the study of the functions of the four codes, including functional code, emotional code, communicational code, and human nature identification code, and the codes of Liushu not only interpreted the rich content of bamboo culture, but also added the scope of using codes.

This study adopted "humanity identification codes" to make up the deficiencies of the three codes: (1) operations that can identify various objects; (2) images that can express various objects that users want; (3) allow consumers to select products that communicate their taste and emotions. The design of such decorative codes can better meet and respond to the needs of consumers.

In the process of participating in the production of the bamboo "Emperor chair" and "Empress chair", we have experienced and discovered that the application of Western codes focuses more on the form (style) of the work and the communication of the five senses, such as their art sculptures. Applying the codes of the Chinese "Six Books" intends to address the recognition of human nature, the symbiosis, and complementary aspects between heaven, earth, and people, for example, their landscape paintings. All present the realms of truth, kindness, and beauty in bamboo furniture decoration design. If we can properly integrate the Chinese and Western codes, combine nature and humanities, and make full use of codes from both cultures, then bamboo furniture decoration and design will be compatible with "Chinese and Western codes", and demonstrate the innovative characteristics of "traditional bamboo craftsmanship". This will not only provide and guide a new direction and new style of Taiwan bamboo furniture decoration and design but also inherit the cultural essence of traditional craftsmanship and enable the sustainable development of "traditional bamboo craftsmanship".

Author Contributions: S.-H.W. contributed to the conceptual design of the study, data collection, drafting the article, and final approval. K.-K.F. contributed to the supervision of the progress, and final approval. C.-J.S. contributed to the software and visualization. All authors have read and agreed to the published version of the manuscript.

Funding: This research did not receive any external funding, nor was it funded by the foundation.

Institutional Review Board Statement: Not applicable.

Informed Consent Statement: Not applicable.

Data Availability Statement: Not applicable.

Conflicts of Interest: The authors declare no conflict of interest. 


\section{References}

1. The Bruntland Commission. Our Common Future, United Nations General Assembly. 1987, p. 43. Available online: Sustainabledevelopment.un.org (accessed on 7 February 2021).

2. Wang, Y.H. The Benefit of Bamboo Forest Management to Reduce the Greenhouse Effect. Spec. Issue For. Res. $2011,18,1$.

3. Chung, K.F.; Yu, W.K. Mechanical properties of structural bamboo for bamboo scaffoldings. Eng. Struct. 2002, $24,429-442$. [CrossRef]

4. Ghavami, K. Bamboo as reinforcement in structural concrete elements. Cem. Concr. Compos. 2005, 27, 637-649. [CrossRef]

5. Ghavami, K.; Marinho, A.B. Physical and mechanical properties of the entire bamboo stem of the species Guadua angustifolia Species. Rev. Bras. Eng. Agric. Ambient. 2005, 9, 107-114. [CrossRef]

6. Sonpal, B.K. Relooking at Bamboo: A Journey into Exploration of Bamboo Components for Structural Possibilities. In Proceedings of the 10th World Bamboo Congress, Damyang, Korea, 17-22 September 2015.

7. Vos, V.D. Bamboo for Exterior Joinery. Master's Thesis, Larenstein University, Leeuwarden, The Netherlands, $2010 ;$ p. 82.

8. Ehrenfeld, J.R. Industrial ecology: A framework for product and process design. J. Clean. Product. 1997, 1-2, 87-95. [CrossRef]

9. Tu, J.C. Product Sustainable Design—Green Design in Theory and Practice; Asia Pacific Book: Taipei, Taiwan, $2005 ;$ pp. 23-35.

10. Bovea, M.D.; Vidal, R. Materials selection for sustainable product design: A case study of wood based furniture eco-design. Mater. Des. 2004, 25, 111-116. [CrossRef]

11. West, J.A.; Louys, J. Differentiating bamboo from stone tool cut marks in the zoo archaeological record, with a discussion on the use of bamboo knives. J. Archaeol. Sci. 2007, 34, 512-518. [CrossRef]

12. The Six Methods of Forming Chinese Characters. Available online: https://tw.answers.yahoo.com/question/index?qid=200712 19000016KK07631 (accessed on 7 February 2021).

13. De Saussure, F.; Riedlinger, A.; Sechehaye, A.; Bally, C. Course in General Linguistics/[by] Ferdinand de Saussure; Bally, C., Sechehaye, A., Baskin, W., Eds.; Fontana: London, UK, 1974.

14. Lin, M.H. Symbols and Codes in Product Modeling. J. Des. 2000, 5, 73-82.

15. Ernst Cassirer (1874-1945). "Semiotic Aesthetics", "Philosophy of Sign Form”. Available online: https://zh.wikipedia.org/w/ index.php?title=Special:\%E6\%90\%9C\%E7\%B4\%A2\&search=Ernst+Cassirer\&ns0=1 (accessed on 7 February 2021).

16. Eco, U. A Theory of Semiotics; Indiana University Press: Bloomington/London, UK, 1976.

17. Li, D.J.; Sun, W.W. Artistic Symbols of Ming and Qing Furniture; China Agricultural Science and Technology Press: Beijing, China, 2013; p. 123.

18. Identifier Definition, University of Glasgow. "Procedure for Applying Identifiers to Documents". Available online: https: / / en.m.wikipedia.org/wiki/Identifier (accessed on 5 June 2011).

19. Smith, C.L.; Brooks, D.J. Security Science: The Theory and Practice of Security; Elsevier, BH: Amsterdam, The Netherlands, 2013.

20. Kodl, J.; Lokay, M. Human Identity, Human Identification and Human Security. In Proceedings of the Conference on Security and Protection of Information, Idet Brno, Czech Republic, 9-11 May 2001; pp. 129-138.

21. Xu, S. (A.C.30), a Native of Zhaoling in Runan of the Eastern Han Dynasty, "Analytical Dictionary of Characters Language" and "Liushu" to Explain Characters. Available online: https:// zh.wikipedia.org/wiki/\%E8\%AF\%B4\%E6\%96\%87\%E8\%A7\%A3\%E5 $\%$ AD \%97 (accessed on 8 February 2021).

22. Ross, S.D. A Theory of Art: Inexhaustibility by Contrast (SUNY Series in Philosophy); State University of New York Press: New York, NY, USA, 1982.

23. Chinese Classical Furniture: Overview of Various Manufacturing Processes. Available online: https://kknews.cc/culture/lekvob. html (accessed on 8 February 2021).

24. Lien, Y.T. General History of Taiwan; General History of Taiwan Press Publishing: Taipei, Taiwan, 1920.

25. Li, Z.S. 20th Century Taiwanese Bamboo Craft; Artist: Taipei, Taiwan, 2000.

26. Kengo Kuma \& Associates, Bamboo House Commune by the Great Wall. Available online: https://archeyes.com/communegreat-bamboo-wall-kengo-kuma-associates / (accessed on 15 March 2021).

27. Wu, S.H.; Cheng, Y.P.; Chen, C.H. Comparative Study of Traditional Craft and Modern Design of Bamboo Furniture. Ind. Des. 2004, 32, 202-207.

28. Ary, D.; Jacobs, L.C.; Razavieh, A. Introduction to Research in Education; Harcourt Brace College Publishers: New York, NY, USA, 1996; pp. 474-496.

29. Chen, C.H.; Cheng, Y.P. Research on the Application of Style Theory to Explore the Style of Chairs in Ming Dynasty. J. Des. 2000, 10, 87-104.

30. Danielle, S. Reviewed by: Michelle S, The Difference Between Structured \& Semi-Structured Interviews in Qualitative Research. Available online: https://bizfluent.com/info-8220458-advantages-interview-over-questionnaire.html (accessed on 8 February 2021). 